International Journal of Social Science and Economic Research

ISSN: 2455-8834

Volume:06, Issue:01 "January 2021"

\title{
CONVEYING THE BELIEF IN NAGA OF THE TAI LUE PEOPLE IN THE UPPER MEKONG MULTICULTURAL SOCIETY
}

\author{
Luxamun Boonrueng \\ Ph.D. Candidate (Education), Faculty of Education, Chiang Mai University, Thailand \\ DOI: 10.46609/IJSSER.2021.v06i01.020 URL: https://doi.org/10.46609/IJSSER.2021.v06i01.020
}

\section{ABSTRACT}

Research titled "Conveying the Belief in Naga of the Tai Lue People in the Upper Mekong Multicultural Society", the objective is (1) to study the evidence of the origin of the thoughts and beliefs of the Naga of the Tai Lue people in the upper Mekong culture (2) to analyze the symbolic meaning of Naga and to convey the belief stories of Naga that appear in the form of fine art and activities of the Tai Lue people, and (3) to study the relationship between people in the Upper Mekong cultural district through the spiritual and religious process of Naga.Use qualitative research methods by collecting data from documents and field research, with nonparticipatory observation methods, engaging observation methods, unstructured interviews, and in-depth interviews, in the Tai Lue study area in Tai Lue autonomous region Sibsongpanna district of the People's Republic of China and Tai Lue in northern Thailand. The research was then used to provide knowledge to Tai Lue youth, in Ban Luang Nuea, Doi Saket District, Chiang Mai Province, Thailand. The study of the origin of the Naga beliefs of the Tai Lue people, it was found that the origin of the Naga beliefs was due to the cult of snake worship and the livelihood of agricultural societies that rely on natural water to nurture life, it is a common belief in the Mekong Basin. Which the belief in Naga has been created as fine art, it is a tradition and a ritual that conveys the symbolic meaning of the wisdom and knowledge of the Tai Lue people, such as Buddhist beliefs, good deeds, the presence of traditional ownership of the Tai Lue people in the Mekong Basin, the introduction of the wisdom of the art of Tai Lue, the expression of the Tai Lue lifestyle that binds to the river, the adaptation to the living environment, the representation of the traditional norms of Tai Lue in the Mekong, the representation of the kinship and family, the expression of the knowledge of nutrition and the relationship between the tribes and the ethnic communities, where the Tai Lue people have a way of conveying their beliefs and wisdom. Traditionally, it is from the experience of the broadcaster to the offspring through the daily lifestyle and social organizing of the community, by participating in activities within the community while conveying current beliefs and knowledge through a formal community network organization. Include temples, schools, municipalities, and 


\section{International Journal of Social Science and Economic Research}

ISSN: $2455-8834$

Volume:06, Issue:01 "January 2021"

learning centers. In terms of the relationship of people in the Mekong Basin through the thoughts and beliefs of Naga, it was found that people in the Mekong Subregion were associated with Buddhism. The Naga is a magical animal that protects Buddhism and is a symbolic animal that represents the annexation of traditional beliefs and ancestral beliefs with religious beliefs. This belief is conveyed and derived from the connection between the Mekong River, this is the region's main river, in a multicultural society, and the belief of Naga reflects that people in the Mekong region are associated with a brotherly home, because of common beliefs and similar traditions.

Keywords: Beliefs, Naga, Tai Lue People, Multicultural Society, Upper Mekong

\section{Introduction}

"Belief" is a natural thing to humans and is considered a source of human culture, the life of humans in ancient times relied on the natural environment around them, while the growth in technology and knowledge is low when something happens naturally. In addition to human control, humans are believed to be inspired by the power of supernatural things, whether it be angels, ghosts, thou shale's, such as rain, thunder, lightning, earthquakes, volcanic eruptions, floods, and rhetoric, etc.(Lanchakorn Nilkarn, 2018) Which, some of the phenomena are beneficial events, but some events are detrimental to their lives and well-being, humans are therefore trying to figure out how to produce results positively and to be happy for themselves and society, to act against those things that have power over nature, it is a ritual practice of faith. It affects the concept of thinking and leads to the creation of norms as a guideline for practice, birth is a tradition, ritual, fine arts, and lifestyle style, etc. collectively called "culture". (Supattra Supap, 2000)Some of the beliefs when it comes to influencing people are thinking systems in society. It often produces certain actions that are characteristic in response to faith and inheritance, it has become a form of knowledge in various forms, and it is a tangible cultural heritage, such as monuments, historical building blocks, churches, cathedrals, mosques, musical instruments, Buddha images, doors, stairs, painting, clothing, ornaments, food, and handicrafts, etc., and intangible cultural heritage such as storytelling, folk songs, poems, performing arts, festivals, traditions, rituals, crafting processes, weaving processes, medical knowledge, knowledge of trees and medicinal plants, languages, and religions, etc.

The belief of "Naga" is an intangible belief culture, and it occurs in the Mekong Subregion, a great and influential culture in the Mekong two communities that demonstrates the traces of ideas and beliefs that appear, it affects the emergence of culture, traditions, rituals, and fine arts. It is a form of knowledge that appears in various forms of literature, tradition, ritual, sculpture, architecture, painting, and the way of life of people on both sides of the Mekong River, since prehistoric times (Chittakorn Emphan, 2002)During the period when Buddhism was not 


\section{International Journal of Social Science and Economic Research}

ISSN: $2455-8834$

Volume:06, Issue:01 "January 2021"

respected until now. For example, the legend of the emergence of the city, whether it is the legend of the emergence of Chiang Saen, the emergence of Luang Prabang, or the story of the emergence of the Khmer people, the tradition of paying homage to Phra That Phanom, and the Naga fireball phenomenon, the new demolition of Tai Lue Sibsongpanna, the farming of Lao farmers in Vientiane, and the Naga serpent of Tai Lue, Sibsongpanna, Laos, and Thailand, etc.This is a testament to the importance of such beliefs that influence the system of thought and the social behavior of the people on the Mekong River. Therefore, the belief in "Naga" has contributed to the creation of the society of various peoples in the Mekong Basin. It is a form of lifestyle, art, and a pattern for people in society to behave or should not be treated, which is the source of knowledge in various fields. Such as artisan knowledge, building houses, building temples, agricultural knowledge, farming patterns, and fish making, etc., knowledge of arts such as fabric patterns, dress, body decoration, or even skin tattooing, and literature, fairy tales, legends, and poetry, including various plays. (Sumet Chumsai Na Ayuthaya, 1986).

Many aspects of the Naka apocalypse and culture have been studied in the past, most of them are interested in studying in the northeastern part of Thailand and the Lao People's Democratic Republic, part of the Mekong Sub-region in the middle of the basin. The Mekong Basin is divided into several standards; geography is divided into two phases: upper and lower Mekong Basins China is divided into the upper Mekong basin and continental Southeast Asia, from Myanmar, Laos, Thailand, Cambodia to Vietnam, to the lower Mekong Basin. However, most scholars in Thailand divide the Mekong into three parts: (1) the upper reaches from the upstream to the Golden Triangle (2) in the middle, from the Golden Triangle to Khone Phapheng or Si Phan Don, and (3) the lower part is Cambodia and Vietnam.But in this thesis, the term "Upper Mekong" refers to the shared culture of the Buddhist community from Lanka through Lanna Chiang Mai to cities in five Chiang cultural groups; Chiang Mai, Chiang Rai, Chiang Tung, Chiang Rung, and Chiang Thong (Luang Prabang) (Phra Kru Wimon Silpakit, 2016) to illustrate the cultural differences between the area and the Chinese, Isan and Khmer cultures due to the northern part of Thailand in Chiang Rai, Phayao province and neighboring groups with similar cultures. Such as the southern area of Yunnan Province People's Republic of China, Shan State, Socialist Republic of the Union of Myanmar, Northern area of Bo Kaeo District Luang Namtha, Phongsalee, and Luang Prabang In the Lao People's Democratic Republic. In the Mekong Basin, as well as evidence of the ancient Naga beliefs, it appears in the form of legends, ancient documents, folk tales, and evidence that appeared in Buddhist art as well. It is also considered that the area is also a symbol of the Naga beliefs that are often referred to in the ancient literature of Isan and Laos. (Satiyaphan Kochamit, 2003)

This study established a study area for the culture and wisdom of the Tai Lue people. Through knowledge from the story of Naga, it is said to be in the Tai people's autonomous region, 


\section{International Journal of Social Science and Economic Research}

ISSN: $2455-8834$

Volume:06, Issue:01 "January 2021"

Sibsongpanna District in Yunnan Province, People's Republic of China, this is the original settlement of the Tai Lue people who are now part of a multicultural Chinese society.And extracted that knowledge to the youth of Tai Lui, at Ban Luang Nuea, Doi Saket District, Chiang Mai Province, which is a Tai Lui area that has been forcibly and immigrated to the multicultural society of northern Thailand, by focusing on studying various knowledge caused by the belief in the serpent of the Tai Lue people who appear in various fields through variables, types, fables, legends, etc. The process of conveying nag beliefs that appear in the community to demonstrate the concepts and beliefs about Naga that influence the thinking system of people in society, these knowledge covers the content of traditions, rituals, wisdom, lifestyle, and fine arts.

The researchers used stories about Naga who had studied them from fairy tales, and the indigenous legend about the Sibsongpanna serpent in Yunnan Province. From collecting field data to the knowledge of the culture of the Tai Lue people in Ban Luang North, Doi Saket District, Chiang Mai Province, Thailand. This is a Tai Lue community that retains its culture well, but is a shortage of tales and cultural narratives, to pass it on to Tai Lue youth at Ban Luang Nuea School, to see the concepts and knowledge of the various aspects, in the story of the Naga it is a way to transfer knowledge to young people in various cultural groups, under multicultural society. The researchers commented that living in a multicultural society is proud and happy. It must be based on understanding its own culture and accepting the cultural differences of other groups.

\section{Research Objectives}

1. To study the evidence of the origin of the thoughts and beliefs of the Naga of the Tai Lue people in the upper Mekong culture.

2. To analyze the symbolic meaning of Naga and to convey the belief stories of Naga that appear in the form of fine art and activities of the Tai Lue people.

3. To study the relationship between people in the Upper Mekong cultural district through the spiritual and religious process of Naga.

\section{Conceptual Framework}




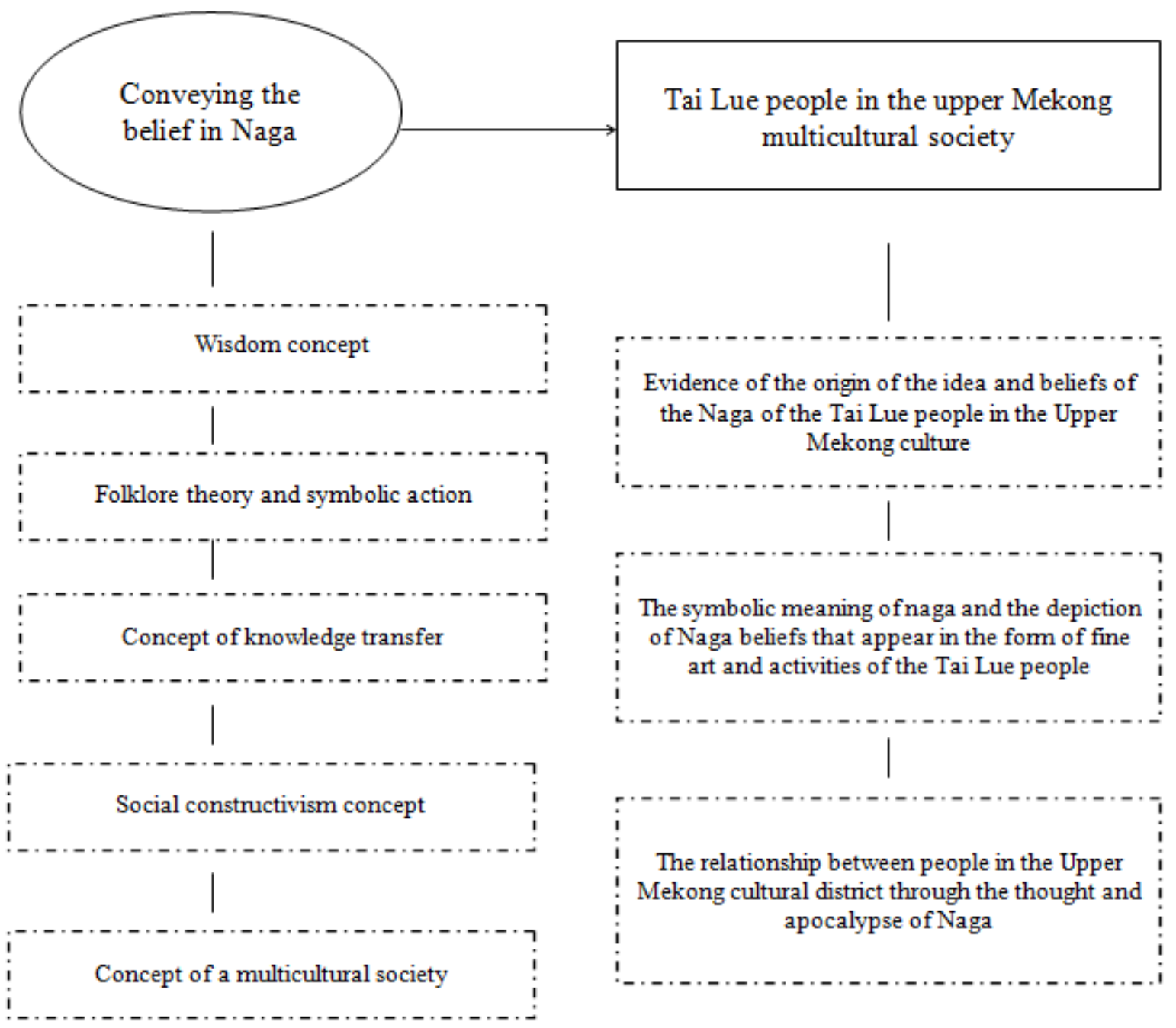

Figure 1: Conceptual framework of the research

\section{Literature Review}

In a study on the transfer of faith in the Naga of Tai Lue people in the upper Mekong multicultural society, the researchers studied the concept of the researchers, and documents involved in the research are sorted by content relationship and the process of use in research studies. As follows:

\section{Wisdom Concept}




\section{International Journal of Social Science and Economic Research}

ISSN: $2455-8834$

Volume:06, Issue:01 "January 2021"

The concept of wisdom is a concept that researchers have used to study the knowledge that lurks in the Naga beliefs, which the researchers believe in the belief of the Naga of the Tai Lue people has been undercover by the wisdom, knowledge of the various aspects of life and the social system of the Tai Lue people in the Mekong sub-region. Therefore, that knowledge must be scrutinized to see the value of the Naga beliefs that appear in the Tai Lue society, both living in the Tai Autonomous Region in Sibsongpanna and northern Thailand.

"Wisdom" is what humans have learned, and experimented to become a valuable model in life. The wisdom is to reach human resources, the knowledge that humans have created to overcome social natural barriers is what helps humans solve problems, which has led to the creation of civilizations in a balanced environment. The word "wisdom" is derived from the English term "wisdom", meaning knowledge, ability, belief skills, and the potential to solve human problems that have been passed down from the past to the present, for a long period. They have their wisdom and are often referred to as local wisdom or local wisdom. (Seree Phongphit, 1993)

Wisdom is not born independently, but it has been exchanged and used to use wisdom from other civilizations from the past to the present. Therefore, in each area, there is a difference in wisdom. This is due to the social interaction of different groups and geography, environments that allow humans to adapt to the environment, combined with the knowledge and knowledge that has been exchanged. It is the wisdom of each local called "local wisdom" or "folk wisdom".In other words, local wisdom is to remove the resources of human resources available in each local area. This can be unique or universal, which many localities have in common. This wisdom stems from the fact that local villagers seek knowledge to overcome natural obstacles, social needed to live local wisdom is therefore related to the production and lifestyle of the villagers, wisdom is a knowledge that consists of virtue.This is in line with the traditional way of life of the villagers traditionally. The lives of the villagers are not divided, but everything is related to livelihoods, community coexistence religious practices, rituals, and traditions. (Ekawit Na Thalang, 2001)

\section{Folklore Theory and Symbolic Action}

Folklore theory and action with this symbol, the researchers foresee the hidden meaning of the Naga beliefs of the Tai Lue people in the Mekong sub-region. Therefore, the theory was chosen in the study, find out the hidden meanings under the story and appearance of the Naga, to express the subject or purpose of the narrative and the creation of a serpent of the Tai Lue serpent, for what reason or meaning the messenger wants to convey to the messenger, in the process of analyzing the meaning of Naga.

\subsection{Folklore Theories}




\section{International Journal of Social Science and Economic Research}

ISSN: $2455-8834$

Volume:06, Issue:01 "January 2021"

Folklore is a science that originated in the 19th century, when scholars became interested in studying the way of life of "villagers" from the folklore, the music that the villagers played the performances of the villagers, the beliefs, and the traditions of the villagers, etc.It was never in the interest of scholars, the word "Folk-Lore", or knowledge of the locals, is the term that William Thoms (1846) the British scholar established.The story of the villagers' way of life has become new information that enables scholars in different countries to study the way of life of lower-level people, and develop theories to be used to understand the meaning and substance sought by the villagers through folklore, which is cultural information that is used as a language instead of the thoughts, beliefs, and imaginations of the villagers. (Siraporn Na Thalang, 2009)Folklore theory is a knowledge derived from the study of the lifestyle and well-being of a group of people who have evolved prominently with a focus on the people whose modern prosperity has not gone very far. These groups of people will continue to have similar lifestyles in a strong relationship, it is thought of the same beliefs and forms of conduct, and is often different from urban or object-prosperous societies. (Malika Kananurak, 2007)

\subsection{Actions between each other by symbol}

The concept of the symbolic system is an important anthropological aspect because it contributes to the cultural appearance that occurs, symbols are necessary for humans to create meaningful systems for the world and nature, because symbolism and interpretation reflect the meaning of culture, there are more than tangible cultural objects, but focus on people's thoughts and perspectives in a person's perspective. Specifically, understanding the thinking system, giving meaning to people as part of a culture a meaningful culture is inserted into the things that humans create or act on, a symbol that exists around humanity in society. That symbol is whatever it is, whether its action, action, events, features, or relationships used as conceptual mediums, are the symbolic systems expressed by humans. (Sanya Sanyawiwat, 2006)

\section{Concept of Knowledge Transfer}

The transfer process is a social process that is constantly running. Therefore, humans absorb the culture and characteristics of society into their personality structure. This learning and absorption are caused by the influence of experience and through the work of social agents, after going through this process, the person will begin to accept until they decide to follow, knowledge transfer is an important process in developing a person's personality in society. This is caused by the fact that a person interacts directly and indirectly with a person or a group of people, and indirectly learns to transfer knowledge and express their behavior. This is the first institution to participate in such a society, this transfer of knowledge will be an ongoing process, a person is inherited from a group of friends, schools, media, and reference groups, which are very important. Because the broadcaster is not affiliated with a member, it influences a person to learn 


\section{International Journal of Social Science and Economic Research}

ISSN: $2455-8834$

Volume:06, Issue:01 "January 2021"

or imitate, such as the behavior of advertisers, movies, and television. This reference group helps individuals learn and convey the way they live in cultural society, allowing them to adapt to change.(Kanchana Kaewthep, 2011)

In summary, it can be said that the transmission is a learning process of succession from one generation to another. This can be done directly and indirectly, through family transfer, with parents being passed on to their children to the behavior and behavior of the beliefs that exist in the community, in direct words, the teaching of guidance, indirectly, is an exemplary act for another generation, the broadcast is consistent with the continuous lifestyle.

\section{Social Constructivism Concept}

The concept of construction is believed to be a social animal with knowledge development. There is a succession of the wisdom of knowledge from generation to generation. When there is an event in your life, it will decide to take any action based on the knowledge that has been done. That knowledge can be learned and conveyed, in the field of study, this concept has been used as the basis for the creation of knowledge as a new theory. It's a story of learning that educators and psychologists find out about how learning in society occurs and how teaching is conveyed. The theory is the cornerstone of the learner's knowledge constructivist theory is a theory that builds the knowledge of learners, which, considering the root of the term "construct" means "build", this means the creation of knowledge by the learner.

Constructor theory believes that learning or creating knowledge is an internal process for learners. The learner is the creator of the knowledge, by bringing experience or what is seen in the environment or new information that has been linked to existing cognition, it is also known as the cognitive structure, also known as "schema". This may not only be information recognition, it consists of the individual bringing the same experience or the original knowledge that they have before, and then create a meaningful understanding of that. However, a person may create a different meaning because of the same experience or understanding. In this regard, the constructivism groups believe that learning is a process of creation rather than knowledge, so the goal of teaching is to support the creation rather than the effort to transfer knowledge, which the construction concept group focuses on creating new knowledge for the individual and believes that the environment is important in creating a real meaning. (Duffy and Cunningham, 1996)

\section{Concept of Multicultural Society}

Multicultural society refers to a diverse group of people of different races, ethnicities, lifestyles, beliefs, religions, and practices that are different, due to the thought and symbolic processes caused by the creation of culture, religious factors, ethnicity, age, gender, social class, and 


\section{International Journal of Social Science and Economic Research}

ISSN: $2455-8834$

Volume:06, Issue:01 "January 2021"

education. This determines that individuals have different ideas, beliefs, feelings, and actions and live together in the same area in society. Therefore, members of society must learn about the rules and regulations that should be behaved or should be ignored by each other's manners in each society, to avoid conflicts that will occur, bring peace of mind to cohabitation and bring understanding to each other. However, Sirichit Sununta (2013) a lecturer in multiculturalism, Mahidol University has given the meaning of multicultural societies that multicultural society refers to a diverse group of people of race, ethnicity, way of life, faith, religion, and traditions, due to the thought and symbolic processes caused by the creation of culture, religious factors, ethnicity, age, gender, social class, and education, this determines how individuals have different thoughts, beliefs, feelings, and actions. This is especially important for Thailand to step into cooperation in the Asian community where there will be more interaction between member states. Therefore, members of society must learn about the rules and regulations that should be behaved or should be ignored according to each other's etiquette in each society, to avoid the upcoming conflict and bring peace of coexistence.

Similarly, Gunew (2001) distinguished between state multiculturalism and critical multiculturalism. In this regard, multiculturalism by state refers to state policies used to address diversity within national states.Many critics see it as a state-controlled, auditing and organizing of differences to strengthen the stability of the state itself. It is based on a liberal concept based on the belief of assimilation and integration under its core powers, because immigrants must finally learn English and Canadian laws before obtaining citizenship status. A multicultural part is a tool used by members of minority communities to demand participation in public spaces based on their differences. There is also a multicultural understanding of the way it is opposed to state unity. In this sense, multiculturalism has some meaning in conjunction with post-colonial concepts. The authors expect that the rise of multiculturalism in Thailand should be considered as a concept because Thailand has never had a formal multicultural policy, contrary to the Thai state, which emphasizes the unity of race and ethnicity and making everyone Thai the rise of multiculturalism in Thai society is counterproductive to the unity of the Thai state, it consists mainly of Thai people.

\section{Methodology}

This research is qualitative research methodology by collecting data from documents and field research, engaging and non-engaging observation methods, unstructured interviews, and in-depth interviews. The study area is the Tai Lue community area in the Tai Lue autonomous region, in Sibsongpanna of the People's Republic of China, and Tai Lue in northern Thailand. The researchers focused on the process of learning the knowledge from the Naga beliefs derived from the study of Naga beliefs to Tai Lue youth. It is a case study with the Tai Lue youth group, Ban Luang Nuea, Doi Saket, Chiang Mai, Thailand. To demonstrate the importance of social identity 


\section{International Journal of Social Science and Economic Research}

ISSN: $2455-8834$

Volume:06, Issue:01 "January 2021"

amid diversity in multicultural societies and to help educate young children and young people, in the Tai Lue community in Thailand, there is a way to research to collect data, as follows:

\section{Research Method}

1) Studying information from related research papers the researchers conducted studies of data from documents related to concepts and theories such as wisdom, folklore theory and symbolic action, knowledge transfer concepts, social constructors, and multicultural social concepts.

2) Field study the tool consists of (1) in-depth interviews based on interview guidelines by interviewing those who know in The Tai in Sibsongpanna Autonomous Region of the People's Republic of China and Chiang Mai, Chiang Rai, Phayao, and Nan. In such matters as those who know about the ritual, the history of the village, who have ordained to study Buddhist teachings, farmers, fishermen, and the stories of nags, snakes, or mermaids (2) unstructured interviews are additional interviews on issues that have not yet been completed (3) non-participatory observation by studying from the context of space, ecology, well-being, water resources, and common resources (4) engaging observation by collecting information by observing and taking notes from the stages of the activities in society, such as religious rituals, creative processes, such as weaving and planting and (5) the survey is a method designed by researchers to study the base of resources that are tied to the community lifestyle and are variants of the birth of the Naga beliefs, by making community planning, eating areas, water resources, and forests, etc.

\section{Scope of research data collection}

This research The researchers will conduct a study on the transfer of the Naga beliefs in the multicultural society in the Upper Mekong, using the Tai in Sibsongpanna Autonomous Region of Yunnan Province, The People's Republic of China, and the Northern Region, especially Ban Luang Nuea, Doi Saket District, Chiang Mai province of Thailand, and sort out the stories about Naga Sibsongpanna, who can extract knowledge to the sample, which is a youth in Ban Luang Nuea, Doi Saket District, Chiang Mai province of Thailand, the scope of the scope is as follows:

1) The area boundaries, areas of study, consist of Tai Lue people in Tai in Sibsongpanna of Yunnan Province, People's Republic of China, and Ban Luang Nua, Doi Saket District, Chiang Mai province of Thailand.

2) Content boundaries the variables in this research are qualitative research using methods of the depiction of literary evidence based on tales, myths, and narratives, which can be extracted as knowledge, covering history and archaeology, literature, traditions, rituals, art forms, lifestyles, and wisdom. The study was based primarily on folklore and the analysis of the population studied was the Tai Lue people, which are a minority ethnic group of both areas and a sample of 


\section{International Journal of Social Science and Economic Research}

ISSN: $2455-8834$

Volume:06, Issue:01 "January 2021"

knowledge from the Naga story. Which is a group of youthful homes above the primary education level 5-6, a total of 20 people from Ban Luang Nuea School, Luang Nuea Sub-district, Doi Saket District Chiang Mai Province, Thailand.

\section{Case Study Selection Criteria}

Because the Tai Lue communities are scattered throughout the country, especially in the northern region, researchers have selected the Tai Lue community at Ban Luang Nuea, Doi Saket District, Chiang Mai Province of Thailand, is a case study of bringing the knowledge gained from the beliefs of Naga to pass on to young students at Ban Luang Nuea School. This area is very different from the traditional area of the Tai Lua ethnic group, which is far from the Mekong River, the main river, close to the main culture of the region. This is a large province, it is a new multicultural society, but it retains its cultural style to a certain extent, and since this group of children are of a certain age with a certain amount of basic knowledge and enough knowledge of Naga. This enables them to expand their knowledge transfer using the appropriate method stipulated in the social construct framework. The school also places importance on the wisdom of Tai Lue, by inviting local scholars to learn about the school every Friday. The village also has Wat Sri Mung Muang and Tai Lue Ban Bai Boon Cultural Learning Center, a center for Tai Lue wisdom.

\section{Data analysis}

For past knowledge transfer models using the concept of knowledge transfer to analyze the model for knowledge transfer in Tai Lue society in the Tai Lue Autonomous Region in Sibsongpanna and Northern Thailand. The knowledge extracted from the Naga faith is passed on to the youth, the concept of social constructs is the main. Choosing how to convey using multicultural social concepts is the basis of research. This is to explain, link, and interpret the actions, activities, meaning, relationships, and social conditions, and then draw conclusions from the information and present it by descriptive method, which is detailed as follows:

1) Faith and knowledge derived from faith, analyzing data using local wisdom or wisdom, folklore theory, and symbolic action, studying the context of the various beliefs that Naga are descriptive of, such as good and evil, Buddhist beliefs, beliefs about preservatives, beliefs about the abundance of water and sky, as well as beliefs about traditional local people, etc.

2) Knowledge transfer analyze data using the concept of knowledge transfer and social construction concept by analyzing the results of beliefs that come out in the form of a tangible and intangible cultural heritage such as arts and crafts, fabric motifs, ink tattoo patterns, architecture, sculpture, painting, food, the process of planting, the process of farming, wedding ceremony, and the texts see Naga provide water, etc.This includes the traditional form of belief 


\section{International Journal of Social Science and Economic Research}

ISSN: $2455-8834$

Volume:06, Issue:01 "January 2021"

and the technique of conveying faith as a guide to conveying faith to Tai Lue youth, the cultural future of the Lue community in Thailand. The experiment sparked a study of the Sibsongpanna knowledge of Naga Sibsongpanna to the sample, which was the youth of the northern house, to see the similarities and differences between Tai Lue in China and Tai Lue in Thailand, this compares to other people living together in northern Thailand.

3) Multicultural society the comparative approach is based on the concept of a multicultural society as the basis for the study. There is a study between Tai Lue in the original settlement that is part of China and the new Tai Lue who settled in northern Thailand and compared to other ethnic groups living together in the case study area of Ban Luang Nuea, Doi Saket District, Chiang Mai, Thailand.

\section{Data presentation}

After the results of the analysis, what comes up is a data set of knowledge of Tai Lue people in various aspects of the Naga faith. This knowledge will be presented by a collection of knowledge, for use as a knowledge set to be conveyed to students in the area, the local area with the population of Tai Lue lives in northern Thailand, in the name of "Tai Lue Cultural Knowledge Series, The North's Catchy House through the tales of Naga Sibsongpanna”.

\section{Results}

In this section, we will discuss the information, knowledge gained from studying Naga beliefs of Tai Lue people in Sibsongpanna from various evidence, applied in transferring to Tai Lue youth at Ban Luang Nuea, Doi Saket District, Chiang Mai Province of Thailand. This is the target area of the experiment. The study compared the knowledge of the Tai Lue community to Ban Luang Nuea with the Tai Lue community in Sibsongpanna and other areas of Northern Thailand, to answer questions about the purpose of the relationship between people in the Upper Mekong cultural district, as follows:

1. Evidence of the origin of the idea the motto of the Naga of the Tai Lue people in the Upper Mekong culture is found, the beginning of the Naga faith in Southeast Asia after the discovery of Buddhism as evidence of history, the origin of the Naga belief in Southeast Asia, after converting to Buddhism, as they were discovered are historical evidence, submitted apostolic nuncio are "Pra Soh $\mathrm{Na}$ Tay Ra" and "Pra Ut Dta Ra Tay Ra" to spread the teachings of teachings to this land and is expected to fuse traditional beliefs into new beliefs. In Southeast Asia, there is a story in the Tripitaka that reflects the fusion of the two beliefs. For example, the legend of the Nagamujarin, the tales of Nagabhumitat. Which is said to be the former incarnation of the Buddha, there are also many local legends about the Naga, and it builds cities in Southeast Asia such as Hongsawadi, Cambodia, Luang Prabang, Vientiane, and Chiang Saen. In the 


\section{International Journal of Social Science and Economic Research}

ISSN: $2455-8834$

Volume:06, Issue:01 "January 2021"

provinces of Thailand where the Mekong River flows, there is often a legend of that Naga serpent. However, he later surrendered to the Buddha and his lord as a guardian of Buddhism, which demonstrates that new beliefs influence the traditional beliefs. So, the origins of the Naga beliefs in the upper Mekong culture the Naga beliefs may be part of the belief in Southeast Asia that existed before the spread of Buddhism into this land. It is also possible to combine the original beliefs from the culture in India, both Buddhism and Hinduism is believed to influence the mindset and livelihoods of people in Southeast Asia. Especially people in the Mekong subregion, nowadays we can find the image of the serpent in the art of temples, religious literature, folk literature, fairy tales, and at festivals, traditions, rituals, or even natural phenomena and social phenomena.The origin of the Naga belief is due to the cult of snake worship and the livelihood of agricultural societies that rely on natural water to nurture life, it is a common belief in the Mekong sub-region, where the belief that Naga has been created as fine arts, traditions, and rituals.

2. Symbolic meaning of Naga and the depiction of Naga beliefs that appear in the form of fine art and activities of the Tai Lue people found that: the symbolic meaning of the wisdom and knowledge of the Tai Lue people, such as Buddhist beliefs, the expression of ownership of traditional areas of Tai Lue in the Mekong Basin, the introduction of the wisdom of the art of the Tai Lue people, the expression of Tai Lue way of life bound to the water, the adaptation to the living environment, the representation of Tai Lue social norms, the representation of relative and family systems, the expression of the knowledge of nutrition and the relationship between Tai Lue people and other ethnic communities, join the region in the Mekong multicultural society, where the Tai Lue people have a way of conveying their beliefs and wisdom. Traditionally, it is from the experience of the broadcaster to the offspring through the daily lifestyle and social organizing of the community, by participating in activities within the community. While conveying current beliefs and knowledge through formal community networking organizations such as temples, schools, municipalities, and learning centers, and the role of Naga, the concept of symbolic action plays an important role in the social concepts and behaviors of a diverse group of people in the Mekong Basin, as follows:

2.1 Naga serpent reflects the image of a traditional group with a lower technology culture than India. It can be seen from early legends or tales of history in Southeast Asia when Indians first came in, they met the Naga or the naked ones.

2.2 Naga reflects the evacuation of the Tai-Lao family or the Tai-Kadai family of people from southern China, in the Nong Sae area of Yunnan province, to the mainstream on both sides of the Mekong River, which appears in the legend of Laos Isan folk legend and the legend of building a country in Lanna. 


\section{International Journal of Social Science and Economic Research}

ISSN: $2455-8834$

Volume:06, Issue:01 "January 2021"

2.3 Naga is a symbol of the kinship system, the second study, the legend of Naga, reflects that in the southern Chinese region of Shan state of Myanmar, in Laos, in the north, northeast, and central Thailand. It was a group of people who had ancestors together and scattered on both sides of the Mekong River before the kingdom of Ayutthaya, which was the same group as the people of the North.

2.4 Naga symbolizes ancestors, reflecting the image of patronage and destruction at the same time. It depends on the morality of the people in society, which is morally adhered to, which is both creative and supportive since the creation of the city. It's always about protecting the city, at the same time, if the people or leaders lack morality, the Naga will destroy the city.

2.5 Naga is a symbol of the preservation of Buddhism and is a propagandist of the teachings, legend has it that when Buddhism entered the Mekong, it clashed with the original belief system, but it could be integrated into one, from the legend of the clash between the Buddha and the head of the Naga group to the Naga became a symbol of the preservation of Buddhism.

2.6 Naga is a symbol of water and abundance, which is expressed by legends that say that Naga is the creators of rivers and fertile plains such as the Mek ong River, Mun River, Ping River, and Kok River, etc.

3. Relationships between people in the Upper Mekong Basin cultural area through the thought process and beliefs about Naga, it was found that: people in the Mekong sub-region are related through Buddhist beliefs. The Naga is a magical animal that preserves Buddhism as a symbolic animal that represents the annexation of the original faith, ancestral beliefs, and religious beliefs, this belief is conveyed and derived from the connection between the Mekong River, this is the region's main river.It is long established that "Naga" has long been associated with the way of life and beliefs of the people of the Mekong sub-region, not only the Northeastern Thais, Khmer, or Lao people only. In the Tai Lue group, both Sibsongpanna and Tai Lue people in other countries, whether in Laos, Thailand, or Burma, there is also a belief in Naga.Which "Nag" is associated with being regarded as an ancestor or the origin of the Tai Lue people, Naga is a sacred symbol, a God of abundance, and the symbol stories and stories about Naga have appeared in the community through works of literature, fine arts, rituals, and phenomena.The belief in both Sibsongpanna and its shared beliefs in the Mekong sub-region reflect the lives of the Tai Lue people and other Tai people. In the agricultural society that relies on the Mekong River, there is a lot of blood in life, but in remote areas, or the new areas of Tai Lue people in the secondary rivers, small rivers, there was never a commonplace in the power of the Mekong, so they were unaware of them in nature.Although there is faith there are many traditions and cultures that can be preserved, but the belief in Naga that interpolates knowledge and Tai Lue 


\section{International Journal of Social Science and Economic Research}

ISSN: $2455-8834$

Volume:06, Issue:01 "January 2021"

wisdom is whatBan Luang Nuea, Doi Saket District, Chiang Mai province of Thailand has a shortage.

\section{Discussion}

A study of the evidence of the origin of the idea and beliefs of the Tai Lue people in the Upper Mekong culture, it appears that the idea of Naga has been in the Mekong sub-region for a long time, it is a common belief in the Mekong sub-region. The origin of the idea is due to the terrain, the climate of tropical rainforests with poisonous animals, abundance, and livelihood in agricultural societies that rely on water from canals. There are both documented evidence and evidence of antiquities that are ancient for thousands of years, such as pottery decorated with snake patterns, from Ban Chiang Archaeological Site Udon Thani Province. Which are evidence of antiquities and the inscription of the Champa kingdom in the 6th century Buddhist, it refers to the Indian Brahmin who married Nang Naga and later descended as an ancestor of the people of the Mekong Basin.The evidence in the Upper Mekong basin is consistent, it shows a longstanding belief in Naga or dragons, and in Sibsongpanna which often mentions the Buddha's visit to cities in the Upper Mekong, meets the Naga who guard the area, and Buddhists are prophesying about those areas that the next will be cities or evidence from the Chinese documents and Sibsongpanna about the origins of the Mekong Basin. The history of the Yunnan Kingdom is that the ancestors of the Kingdom of Nan Chao were of the lineage of the Naga or Dragon, and called the Mekong River "Jiulongjiang River", etc.

The Naga faith is part of the belief in continental Southeast Asia that existed before the propagation of Buddhism into this land and later fused into Buddhism. It may include the original beliefs from cultures in India, both from Buddhism and Hinduism, as well as beliefs that influence the thoughts and livelihoods of people in the Mekong sub-region. Nowadays, images of Naga can be found in temple-based art, religious literature, folklore, fairy tales, festivals, festivals, rituals, rituals, and other things, or even natural phenomena and social phenomena. According to the document, the legend "Pra jao liap lohk" is symbolic evidence that suggests that Naga refers to traditional people living before accepting Buddhism, at least before the 19th century. This is the time when Buddhism spread widespread in the upper Mekong Basin through the study of monks in Buddhism from Lanna to land. Later, when Buddhism was enshrined in those lands, the phenomenon was reflected in the Sibsongpanna, which went down to study the dharma in Lanna and Burma, to trace the religion as well, which is shown in the legend "Pra jao luang chiang kon".

It is long established that "Naga" has long been associated with the way of life and beliefs of the people of the Mekong sub-region, not only in Northeastern Thais and Cambodia or Lao people. The Tai Lue people both at Sibsongpanna and the Tai Lue people in other countries whether in 


\section{International Journal of Social Science and Economic Research}

ISSN: $2455-8834$

Volume:06, Issue:01 "January 2021"

Laos, Thailand or Myanmar, believe in Naga as well. In this regard, "Naga" is regarded as an ancestor or the origin of the Tai Lue people, which is a sacred symbol, a god of abundance, symbols and stories about Naga, appearing in the community through literary, fine, and ritual works, and the phenomenon of the belief in both Sibsongpanna and the common belief in the Mekong sub-region. It reflects the lives of the Tai Lue people and other Tai people. In the agricultural society that relies on the Mekong River, there is a lot of blood in life. However, in remote areas, or the new areas of Tai Lue people in secondary rivers and small rivers, they have never encountered the power of the Mekong, so they do not know in those natures. Although there is faith there are many traditions and cultures that can be preserved, but the belief in Naga that interpolates knowledge and Tai Lue wisdom is what Meuang Luang lacks.

Conveying the Wisdom of Tai Lue through the tales of Naga based on the lack of information, a series of tales, and the story of the Tai Lue community in Ban Luang Nuea. As mentioned above, as a result, the Tai Lue community Ban Luang Nuea lacks the important tools to transfer knowledge to young people, while studying the beliefs of the Naga of the Tai Lu people in the Tai People Autonomous Region at Sibsongpanna. The researchers found that the serpent was involved in various contexts in the life of the Tai LueSibsongpanna people in various aspects of literature, religion, society, fine arts, this includes sculpture, architecture, painting, and handicrafts, traditions, rituals, including social phenomena and natural phenomena. These can be reflected in the knowledge or wisdom of the Tai Lue people in a variety of ways. Through the rich tales and stories in Sibsongpanna, the knowledge of the home community itself is already in various aspects, except for the stories that have been presented. In addition to the pattern of knowledge transfer according to the process chosen by the sage Tai Lue, Ban Luang Nuea has chosen to transfer knowledge to their youth. The researchers then devised a project to learn Tai Lue culture through the story of Naga, passed on to the youth Ban Luang Nuea. It selected five local legends and tales about Naga that were fun and interspersed with the wisdom of Tai Lue. This is a story that the researchers acquired from a trip to study. The search was based on the cities of Tai Sibsongpanna, the People's Republic of China, and is a missing part of the Ban Luang Nuea community, to express the symbolic meaning of the knowledge and wisdom of Tai Lue Sibsongpanna and encourage young people to think in comparison with the knowledge and wisdom of Tai Lue in their communities. It concludes the relationship between the people in the Mekong sub-region and the Ban Luang Nuea community as well as the multicultural and ethnic people. However, they can coexist under their ethnic identity, this is an important aspect of Southeast Asia's multicultural society that has been learning and comparing cultures in the past.

After that, the plan was prepared through the Naga beliefs, it selected Sibsongpanna broadly known tales with fun and concealed the wisdom of Tai Lue, enter the process of conveying in various forms according to the constructivist Theory social concept. It is believed that children 


\section{International Journal of Social Science and Economic Research}

and young people can build their knowledge through the process of forging from the environment and society, in addition to the stimulation of the instructor, after the plan has been prepared, get in touch with cultural community leaders to learn about the knowledge suite and contact the director of Ban Luang Nuea School, to present the concept of knowledge transfer and to request permission to organize activities according to the project, the cooperation of community leaders is: Thai Wisdom Learning Center Tai Lue Ban Bai Boon presented their local wisdom, and Ban Luang Nuea School has selected Tai Lue ethnic students to join the project, which are 20 students in grade 5 and 6 , and received cooperation from undergraduate students early childhood education faculty of education Chiang Mai University, become a broadcaster by telling stories. And the local sage from the Thai Wisdom Learning Center of The Tai Lue Ban Bai Boon co-author educating the local students to reflect on the idea is the following 4 activities:

(1) The activity of the serpent cognition test before the project began, the research showed that the majority of Ban Luang Nuea youth participating in the project. It is thought that the serpent is a magical animal that represents goodness and resists evil. Therefore, most young people are not afraid of Naga if it's not immoral the look of this Naga, as with other ethnic communities, there is also a belief in Naga. Such as Lao people, Isan people, and Payap Thai people (Tai-Yuan), which can be seen on the stairs to the temple, church, vihara, and painting, when students draw imaginary lines it was found that most of the students draw a picture of a Naga that looks like a snake. But there is a uniqueness that most lyrics are written with a swan and a beard, with a part of the painting of a hill tack and paw, the latter model is characterized by the Tai Lue Sibsongpanna Naga.

(2) Knowledge transfer activities through the storytelling of 5 Naga stories, performances, and media, and the basis of beliefs about snakes, Naga, and dragons internationally. The results showed that the first activity was an activity of faith in nag and universality. This activity allows students to learn the origin of the Naga beliefs developed from the concept of occupation in an agricultural society and the environment. Which is a common cultural trait that occurs all over the world, gives a fundamental view of Naga beliefs and the belief in water from a wide-angle, by observing the questions and answers about the nature of snakes, Naga, and dragons, from different places that appear in different cultures of the world.

The second activity is the legendary activity "liang-pee-nong-dterng-meuang-ham". The youth who participated in the project can conclude as to why the city is swamped. It is caused by the immoral misconduct of the governor or the leader, as well as the power of the Naga that can be transformed into other animals. It can inspire harm to non-moral or social norms under the moral framework of Buddhist goodness. 


\section{International Journal of Social Science and Economic Research}

ISSN: $2455-8834$

Volume:06, Issue:01 "January 2021"

Activity three is the legendary activity "legend-lor-kai-nake-mueang-yang", students give examples of the cuisine of the Tai Lue people at Ban Luang Nuea, which students have seen from experience directly at home, at the temple, or school, students can demonstrate Tai Lue food, it is possible to extract the knowledge from the myth that Tai Lue food is a useful food because it is a natural food, no fat mix, and the fried food with a lot of oil is modern, if you eat a lot, it is useless and negatively affects the body.

Activity four is the legendary activity of "bpa-tom-gan-prom-saang-lohk-sip-song-bpan -naa". The youth who participated in the project learned various components, of Ruan Tai Lue why the need to build a long roof and a raised house. At the end of the activity, students can associate the architectural characteristics of Tai Lue with characteristics associated with animals such as roofs that resemble swallow wings. Under the roof, the interior can be stored like sparrows' nests, red cloth-tied pillars at the master and master pillars. Like a dragon's crest, the long staircase is like a serpent, and the stones that support the pillars, which are like turtles, etc.

Activity five is a "sieow-pee-sieow-kon" activity, which is fun, which is one of the objectives of this story is to build a good relationship between parents and children. This storytelling activity will convey the warmth, trust, and emotional development of the children's age-appropriate thoughts, especially those of children who participate in this activity as primary school children who are entering their teens and will continue to study at high schools in the district and province.

Activity six is an activity "Legend of King Chiang Khor (Kon), the city of lies", where students can give examples of the buildings inside the temple to see what they have and how they act. It then describes the relationships and locations of the cities that appear in legends such as Luang Prabang, Burma, Chiang Mai, and Ayutthaya, It is an important city that is the center of the rule of various nations and is the center of Buddhism.

(3) Activities to remove knowledge of Tai Lue culture from Naga stories and study them within the local Ban Luang Nuea after the five storytelling activities are completed. The researchers met again with students to summarize the essence of knowledge and wisdom, from the five tales of the serpent and the students reflecting on the local wisdom that the local Ban Luang Nuea is the local. It appears to show knowledge related to myths and tales, as well as allowing students to divide them according to the topic of wisdom they think is available in the village to continue their studies. As a result, the wisdom that students can reflect on can be imagined. There are 5 topics available, from the five myths and tales: (1) "liang-pee-nong-dterng-meuang-ham" reflects the knowledge of virtue, morality that humans should do (2) "legend-lor-kai-nake-mueangyang" Reflecting the knowledge of Tai Lue folk food (3) "bpa-tom-gan-prom-saang-lohk-sipsong-bpan-naa" reflects the knowledge of architecture and planting of Tai Lue houses (4) "story 


\section{International Journal of Social Science and Economic Research}

ISSN: $2455-8834$

Volume:06, Issue:01 "January 2021"

sieow-pee-sieow-kon" reflects the knowledge of society, the community of Tai Lue people and the organs in the body (5) "Legend of King Chiang Khor (Kon), the city of lies" reflects the knowledge of the temple's architecture and its interaction with the neighborhood.

(4) Tai Lue cultural knowledge summary activity in Ban Luang Nuea, where young people receive and prepare a set of cultural knowledge, Tai Lue Ban Luang Nuea. Through the tale of Naga Sibsongpanna, a summary of the knowledge that students receive through the story of Naga Sibsongpanna and then bring that knowledge to the local knowledge of the same content, the summary is a series of knowledge. By giving students a record of knowledge that is consistent with the faith of Naga in Sibsongpanna and appearing to find the same faith in their own Ban Luang Nuea community, writing them into an article is a collection of cultural knowledge of Ban Luang Nuea through tales of Naga Sibsongpanna. Also, the group is divided into five articles as follows: (1) the old-fashioned knowledge of Ban Luang Nuea from learning about virtue, a morality that humans should do (2) the diet of Tai Lue people Ban Luang Nuea from learning about the nutrition of Tai Lue folk food (3) the creation of Tai Lue house and beliefs about the house by learning about architecture, the wisdom of building Tai Lue (4) Tai Lue's social system Ban Luang Nuea from learning about the social system of the Tai Lue people (5) Architecture at Wat Sri Mung Muang from learning about Naga serpents and Buddhism and the architectural elements within the temple.

According to the study of cultural wisdom relay at Ban Luang Nuea Sub-district, Doi Saket District, Chiang Mai Province presents a way of conveying knowledge from the Naga beliefs to the youth of Ban Luang Nuea. Myths, tales, or stories are important tools in the process of transferring knowledge to young people, and animal tales are the most common stories that children like because they are fun stories. This can be infused with the knowledge contained in the contents of the story in an empirical way. In particular, tales related to Naga, which are imaginary animals of people in the Mekong sub-region, should be a good tool to transfer knowledge to young people. Therefore, the five legends and tales from Sibsongpanna were selected through the process of telling stories for the youth in Ban Luang Nuea reflected their knowledge and searched for the same knowledge from their local area, presented as a short article is a series of cultural knowledge of Tai Lue Ban Luang Nuea through the tales of Naga Sibsongpanna. The results of the knowledge of Naga beliefs to the youth Ban Luang Nuea appears to be based on the original knowledge of the Naga of the youth in Ban Luang Nuea. The environment of the village is far from the large river, the belief in Naga faded away from the village, it is only found at Wat Sri Mung Muang.

The storytelling activities of the show make the youth feel fun and engaging, while simultaneously absorbing the culture of Tai Lue's traditions through storytelling and participation in the show. Also, the activities of Tai Lue culture knowledge derived from fairy tales to the 


\section{International Journal of Social Science and Economic Research}

ISSN: $2455-8834$

Volume:06, Issue:01 "January 2021"

knowledge and wisdom of the Tai Lue community in Ban Luang Nuea enables young people to reflect their knowledge and wisdom in their communities, work together as a group, analyze and interact with the elderly, which are local sage, forming a bond in the community. As well as the activities of the knowledge summary and the preparation of a series of cultural knowledge, the house is deceived over through tales of Naga Sibsongpanna, by the youth of Ban Luang Nuea, children can practice descriptive writing skills, practice working together as a group has reviewed the knowledge from what has been learned throughout the activity in comparison, the knowledge of the Naga Sibsongpanna story and the knowledge of their community. As well as being absorbed and proud of their own culture which knowledge that children have written out is a valuable product this can be used as a knowledge pack in elementary school classrooms of Ban Luang Nuea School.

\section{Conclusions and Suggestion}

From the study of ideas the motto of the Naga of the Tai Lue people in the upper Mekong culture. The role of Naga, if used with symbolic action concepts, is found to play an important role in the social concepts and behaviors of a wide range of people in the Mekong basin, as follows:

1) The Naga serpent reflects the image of a traditional group with a lower technology culture than India, as you can see from the legends or early tales of history in Southeast Asia, Indians first came in and met the Naga or the naked ones.

2) Naga reflects the evacuation of the Tai-Lao family or the Tai-Kadai family, from southern China, Nong Sae, Yunnan province, came to settle on the two banks of the Mekong River, which appeared in the legend of Laos Isan folk legend and the legend of building a city in Lanna.

3) Naga is a symbol of the kinship system, which is the result of the 2nd study of the legend of Naga, reflecting that the group of people in the southern Chinese region in the Shan state of Myanmar, in Laos, in the north, northeast, and central Thailand, are all groups of people who have common ancestors and are scattered on both sides of the Mekong River, before the birth of Ayutthaya, it was the same group as the people of the North.

4) Naga symbolizes ancestors, reflecting the image of patronage and destruction at the same time. It is based on the morality of the community, which is adhered to morally and morally, is that Naga is creative, supportive, and supportive, from the construction of a ban on the city, as well as the protection of the city to happiness. At the same time, if the people or leaders lack morality, Naga will destroy the city. 


\section{International Journal of Social Science and Economic Research}

ISSN: $2455-8834$

Volume:06, Issue:01 "January 2021"

5) Naga is a symbol of the preservation of Buddhism and is a propagandist of the teachings of legend "Urangkathat" shows that when Buddhism enters the Mekong, it is a clash with the original belief system, but can be integrated into one, from the legend of the clash between the Buddha and the head of the Naga group to the Naga became a symbol of the preservation of Buddhism.

6) Naga symbolizes water and abundance, which are expressed by myths that say that Naga creates rivers and fertile plains, such as the Mekong River, Ou River, Ngum River, Moon River, Ping River, and Kok River, etc.

In this regard, the relationship between people in the upper Mekong cultural district through the thought and apocalypse of Naga, people in the Mekong sub-region are related through Buddhist beliefs, it is now the northern part of Thailand as a Buddhist template. While the ground of the original belief is a common belief about supernatural powers, in tropical geography, there are a lot of poisonous animals, visiting each other through the water trails, especially the Mekong River. This is why Tai groups are connected and receive cultural patterns, but they are adapted to the environment in their own space. The Naga faith is a fundamental belief rooted in the minds of people in the Mekong sub-region. Based on this idea, it has created traditions and cultures, as well as artifacts, as well as tangible cultural heritage, such as objects, appliances, sculptures, architecture, inventions, and intangible cultural heritage, such as thought processes, arts, and knowledge in cooking Knowledge of herbs, medicine, processes of traditions and rituals, etc.

Therefore, the researchers have suggested for further study: in the field of Naga beliefs, which are presented as evidence of various types of evidence, including literary evidence, art, traditions, rituals, and natural phenomena social phenomena can also be studied in depth in detail of various aspects of the evidence that will bring specific knowledge. For example, the knowledge and meaning of Tai Lue's flake-shaped leg tattoo, the pattern, and belief of the Lao Naga pattern, or the Naga art adorned with Tai Khoen Buddhists in Chiang Tung.

Ban Luang Nuea community area is a case study area for this research, the people of Tai Lue at Ban Luang Nuea are very proud of their richness, and there is a cultural center of wisdom for the children Ban Luang Nuea Moo 4 and Moo 5 are among the top mentions. When it comes to Tai Lue traditions and culture in Thailand, it has been awarded by several government agencies and organizations. Moreover, it was found that the representatives of the leaders of the Ban Luang Nuea community were committed to conveying the wisdom they had to the youth through the school education system in Ban Luang Nuea school in the local wisdom hours and wellcooperated with the teachers. 


\section{International Journal of Social Science and Economic Research}

ISSN: $2455-8834$

Volume:06, Issue:01 "January 2021"

The Tai Lue people at Ban Luang Nuea are trying to restore the knowledge of their ancestors, through the Naga motto, which is the traditional belief of the Tai Lue people in Sibsongpanna, from a cultural exchange trip with the Tai Lue Sibsongpanna people in China. The royal temple of Wat Sri Mung Muang is filled with Naga-shaped sculptures and the idea of the origin of the village name. From the catchy native myth Sibsongpanna about "dtua luang", the two animals are imaginary creatures that combine the patterns of many animals. It is meant to be auspicious about abundance, honesty, respect, fear, and connection with Buddhist beliefs, so it has been used to restore Tai Lue beliefs and wisdom.

The Naga faith is a fundamental belief rooted in the minds of people in the Mekong sub-region, based on this idea, the concept has created traditions, cultures, and artifacts such as artifacts, sculptures, architecture, artifacts and intangible cultural heritage, such as thought process, performing arts, culinary knowledge, knowledge of herbs, medicines, processes of tradition and rituals, etc. Therefore, the researchers have a suggestion for those who will study further in the field of knowledge transfer, should be researched in the process of conveying knowledge to provide information and use it as a guide to choosing the right method for the transfer of knowledge, for classroom education Informal education and informal education.

In Thai society, we always see symbols about Naga, painting, sculpture, and handicrafts are also featured in paintings, sculptures, and handicrafts. "Naga" is considered an important architectural component, especially according to the temples, the roof of the building built for the monarchy, and the religious institutions, according to the motto that the great nag is worthy of noble institutions. For example, the "Nak sa-dung" that stretches along the stairs of "Nak lam-yong" is a church roof that connects to Nak Sa-Dung, Nak beuan, Nak jam-long, and Nak tan, which is crutches under the Naga-shaped eaves.

In society, community, locality, knowledge of Naga stories are introduced in various art, literature, painting, architectural elements, and folk crafts, as well as in beliefs, traditions, and rituals. For example, sculpture and painting, the story of Naga in Buddhist history, and prom national are used as painting. Also, Naga-shaped sculptures appear as elements of the church architecture, the temple's temples. Crafts such as woven fabrics are patterned, which young women of Tai Lue are very skilled at weaving because they are trained by their mothers and female relatives. The creative design of Tai Lue fabric is considered to be beautiful. Which can be made into various patterns can be done with many techniques with an emphasis on the pattern of Naga, swan, and castle, etc. They made woven fabric that is used for family apparel, as well as bedding, pillows, and blankets, etc. However, if wanting to make merit, they will weave Tung, or cloth used in Buddhism at the temple create a charity for women instead of ordination. 


\section{International Journal of Social Science and Economic Research}

ISSN: $2455-8834$

Volume:06, Issue:01 "January 2021"

"Knowledge Transfer" is very necessary for one society because good learning occurs when it is distributed and conveyed quickly and appropriately to society, which is about the distribution of knowledge between one people to another, it is possible intentionally and unintentionally, such as writing, training, meetings, and communication through publication or work turnover, experience talking in local context the process of knowledge transfer is in the manner of the birth and the transfer of wisdom to the villagers, this is both written through system learning and from experience. This research brings new knowledge that affects society, local, and community. The process of transferring knowledge through the Naga faith to the Tai Lue community, which the researchers used as a tool to analyze the resulting data of Tai Lue's inheritance of wisdom, in both the Tai Sibsongpanna autonomous region and the northern part of Thailand. In the form of the transfer and factors of the Naga beliefs and knowledge of Tai Lue that are contained in the tales, myths, stories, and cultures of the Tai Lue people, and the techniques for how to convey to Tai Lue youth what is appropriate to the Tai Lue community in Ban Luang Nuea, Luang Nuea Sub-district, Doi Saket District, Chiang Mai Province.

\section{References}

Anukulwathaka, N. 2011. "The process of restoring the historical consciousness and the establishment of Thai Lue culture. Chiang Kham Community, Phayao Province ". Master of Arts Thesis (History) Graduate School Chiang Mai University.

Boonarapa, O. 1981. "Naga in Sanskrit and Pali literature”. Master of Arts Thesis Chulalongkorn University.

Chumsai Na Ayuthaya, S. 1986. Water, the source of Thai culture. Bangkok: Thai Wattana Panich.

Emphan, J. 2002. "The Serpent, Lord of the Mekong River: Rituals and the Cultural Folklore System Isan". Master of Anthropology Thesis, Faculty of Political Science, Chulalongkorn University.

Holt, H. 1988. A Thousand Miles on Elephant in the Shan State. Bangkok: White Lotus Reprint.

Jumsai, S. 1997. Naga Cultural Origins in Siam and the West Pacific. Bangkok : Chalermnit Press \& DD Books.

Kantha-in, P. 2004. "The transmission of beliefs in Buddhism by the Dharma Practice Center in the North". Master of Education Field of Study in Non-Formal Education Chiang Mai University. 


\section{International Journal of Social Science and Economic Research}

Kochamit, S. 2003. "Development of the Naga beliefs in the Mekong River from the Urung period to contemporary history. Master of Arts Thesis Faculty of Arts, Chulalongkorn University.

Mayoury and Ngaosrivathana, P. 2009. The Enduring Sacred Landscape of the Naga. Bangkok : O.S. Printing House.

Panyakaew, W. 2012. Lue Cross-border: The Journey of Lue Young People, Muang Yong, Shan State, Burma. Chiang Mai: Center for Research and Academic Service. Faculty of Social Sciences Chiang Mai University.

Premchit, S. 2005. Lanna Scripture Interpretation Project Interpret and analyze Lanna law.

Chiang Mai: Mahamakutrajavidyalaya University Lanna Campus.

Promchai, O. 2006. “About medical treatment with herbs”. Master of Education Thesis (Non-formal education) Graduate School Chiang Mai University.

Rodhetphai, C. 1974. Thai Lue Literature, Yuen Sub-district, Chiang Kham District, Chiang Rai Province. Bangkok:Printing Teachers' Council Ladprao.

Rojsangha, A. 2017. "Living and the way of life of Tai Lue community Northern illusory

House". Documentation of the National Conference Program 2nd Academic Fine Arts: Art 4.0 Art for Creativity and Art for education Faculty of Fine and Applied Arts Srinakharinwirot University.

Setthakul, R. 1999. Research report Influence of social and cultural beliefs on development. Thai state: a case study of Tai Dam, Lue and Yuan. Thai National Culture Research Project, Bangkok: Office National Culture Commission.

Setthakul, R. 1984. Ethnic Survey of the Tai Tribe in the Ping River Basin. Chiang Mai Province. Research Report No. 1, Payap University Research project to develop higher education institutions from the university bureaus $1983-1984$.

Srisawat, B. 2004. Thai Sipsongpanna. Volume 1, Volume 2, 3rd edition. Bangkok: Siam Publishing House.

Suriyameha, O. 2015. “Ramkhamhaeng Journal Humanities edition”. Year 34, No. 1 (January-June), pages 128-146.

Thirateep, N. Co. 2000. “Changes in Tai Lue society, Luang Nuea sub-district, Doi Saket 
district, ProvinceChiang Mai 1917-1997: Study through characteristics and networks offormal leadership relationships". Master of Arts Thesis (History) Graduate School Chiang Mai University.

Vejchasat, V. 2012. Concept of Naga of the Thai people. Nakhon Pathom: Silpakorn University, ReportResearch grants for research from the Institute of Research and Development. Silpakorn University.

Zander, R. 2002. Naga in Temple Architecture Origins in Khmer Art and Developments in Northern Thailand. A fieldwork project college year in Thailand program academic year 2001 - 2002 Chiang Mai University, University of Wisconsin Madison. 